\title{
Association of the C825T polymorphism in the GNB3 gene with obesity and metabolic phenotypes in a Taiwanese population
}

\author{
Tun-Jen Hsiao • Yuchi Hwang • Can-Hong Liu • \\ Hua-Mei Chang $\cdot$ Eugene Lin
}

Received: 12 December 2011/ Accepted: 1 June 2012/Published online: 12 July 2012

(C) Springer-Verlag 2012

\begin{abstract}
The relationship between obesity and a single nucleotide polymorphism (SNP), rs5443 (C825T), in the guanine nucleotide binding protein beta polypeptide 3 (GNB3) gene is currently inconsistent. In this study, we aimed to reassess whether the GNB3 rs5443 SNP could influence obesity and obesity-related metabolic traits in a Taiwanese population. A total of 983 Taiwanese subjects with general health examinations were genotyped. Based on the criteria defined by the Department of Health in Taiwan, the terms "overweight" and "obesity" are defined as $24 \leqq \mathrm{BMI}<27$ and $\mathrm{BMI} \geqq 27$, respectively. Compared to the carrier of the combined CT + TT genotypes of the GNB3 rs5443 polymorphism, triglyceride was significantly higher for the carrier of CC genotype in the complete sample population $(128.2 \pm 93.2$ vs. $114.3 \pm 79.1 \mathrm{mg} / \mathrm{dl}$; $P=0.041$ ). In addition, the carriers of CC variant had a higher total cholesterol than those with the combined CT + TT variants $(194.5 \pm 36.8$ vs. $187.9 \pm 33.0 \mathrm{mg} / \mathrm{dl}$; $P=0.019)$ in the complete sample population. In the normal controls, both triglyceride $(P=0.018)$ and total
\end{abstract}

\section{T.-J. Hsiao}

College of Public Health and Nutrition,

Taipei Medical University, Taipei, Taiwan

Y. Hwang · H.-M. Chang · E. Lin ( $\square)$

Vita Genomics, Inc, 7 Fl., No. 6, Sec. 1, Jung-Shing Road,

Wugu Shiang, Taipei, Taiwan

e-mail: eugene.lin@vitagenomics.com

C.-H. Liu

Center for Obesity, Taipei Medical University Hospital,

Taipei, Taiwan

E. Lin

Institute of Clinical Medical Science, China Medical University,

Taichung, Taiwan cholesterol $(P=0.011)$ were also significantly higher in the CC homozygotes than in the combined CT $+\mathrm{TT}$ genotypes. However, the GNB3 rs5443 SNP did not exhibit any significant association with obesity or overweight among the subjects. Our study indicates that the CC genotype of the GNB3 rs5443 SNP may predict higher obesity-related metabolic traits such as triglyceride and total cholesterol in non-obese Taiwanese subjects (but not in obese subjects).

Keywords G-protein - Metabolic phenotypes · Obesity · Single nucleotide polymorphisms

\section{Introduction}

Obesity is an important clinical and public health burden, and its prevalence is growing worldwide (Kelly et al. 2008; Ogden et al. 2007). Nowadays, 300 million people in the world are considered obese (Kelly et al. 2008). It is estimated that 1.12 billion people will be obese around the world in 2030 (Kelly et al. 2008). The social and economic costs of obesity are high as obesity elevates the risk of several medical complications, such as type 2 diabetes (T2D), hypertension, dyslipidemia, and cardiovascular disease (Kelly et al. 2008; Ogden et al. 2007). More and more genetic variants associated with obesity are being discovered using candidate gene approaches, genome-wide linkage studies, and genome-wide association studies (Hebebrand et al. 2010; Loos 2009). Identification of genes that contribute to risk of obesity will allow identifying individuals who are at risk, and ultimately it may lead to new therapies for treatment and prevention (Hebebrand et al. 2010; Loos 2009). The search for genes that increase the susceptibility to develop obesity has become increasingly important. One of these 
genes is the guanine nucleotide binding protein beta polypeptide 3 (GNB3) gene.

The GNB3 gene encodes the beta 3 subunit of heterotrimeric G-proteins, which are key components of intracellular signal transduction between receptors and intracellular effectors virtually in all cells of the body (Cabrera-Vera et al. 2003). A common single nucleotide polymorphism (SNP), rs5443 (C825T), located on exon 10 of the GNB3 gene has received much attention. The T allele of the GNB3 rs5443 SNP has been shown to cause enhanced G-protein activation and thus increased in vitro cell proliferation (Siffert et al. 1995). The T allele of the GNB3 rs5443 SNP was identified to be associated with obesity, hypertension, and atherosclerosis (Benjafield et al. 2001; Hegele et al. 1999; Klenke et al. 2011; Poch et al. 2002; Siffert 2005; Siffert et al. 1999). However, evidence for relevance of GNB3 rs5443 to obesity is currently inconsistent. The T allele of GNB3 rs5443 SNP has been reported to predispose to obesity in German (Brand et al. 2003; Siffert et al. 1999; Stefan et al. 2004), Chinese (Siffert et al. 1999), and South African (Siffert et al. 1999) populations. On the contrary, this association with obesity has not been replicated in white Danish subjects (Andersen et al. 2006) and in a Japanese study (Hayakawa et al. 2007). In addition, data from a study support the notion that there was statistically significant association of this SNP with total cholesterol levels in a Japanese population (indicating higher in subjects with the $\mathrm{T}$ allele) (Ishikawa et al. 2000), even though there are some conflicting results in another Japanese study showing no association with cholesterol (Suwazono et al. 2006). Moreover, previous pharmacogenetic studies (Grudell et al. 2008; Hauner et al. 2003; Hsiao et al. 2009) have revealed that the GNB3 rs5443 polymorphism was associated with weight reduction with sibutramine treatment in overweight or obese participants, suggesting either the $\mathrm{T}$ allele (Grudell et al. 2008; Hsiao et al. 2009) or the C allele (Hauner et al. 2003) with greater weight loss.

The relationship between GNB3 rs5443 and obesity remains unclear and needs to be reassessed. The aim of this study was thus to evaluate whether the GNB3 rs5443 polymorphism is associated with obesity and obesity-related metabolic traits in Taiwanese subjects. We performed a case-control association study using obese individuals with a body mass index (BMI) $\geqq 27 \mathrm{~kg} / \mathrm{m}^{2}$ and non-obese controls with a BMI $<24 \mathrm{~kg} / \mathrm{m}^{2}$.

\section{Materials and methods}

Study population

The study cohort consisted of volunteers who underwent general health examinations at the Taipei Medical
University Hospital in Taipei, Taiwan, in 2008. Approval was obtained from the Internal Review Boards of the TriService General Hospital and the Taipei Medical University Hospital before conducting the study. The approved informed consent form was signed by each subject. The study population included 983 participants. Nine participants had incomplete clinical measurements, and two participants could not be genotyped. Thus, we included 972 subjects in the present analysis.

Using the criteria defined by the Department of Health in Taiwan, the terms "normal," "overweight," and "obesity" in this study are defined as BMI $<24,24 \leqq$ BMI $<27$, and BMI $\geqq 27 \mathrm{~kg} / \mathrm{m}^{2}$, respectively (Chu 2005). Height without shoes and body weight in light clothing were measured to the nearest $0.1 \mathrm{~cm}$ and $0.1 \mathrm{~kg}$, respectively. Height was measured using a standard steel strip stadiometer, and weight was determined using a digital electronic scale. BMI was calculated as weight in kilograms divided by squared height in meters $\left(\mathrm{kg} / \mathrm{m}^{2}\right)$. Waist circumference was measured at the midway point between the lower rib margin and the superior iliac crest in a horizontal plane with flexible anthropometric tape.

In addition, the systolic and diastolic blood pressures, serum total cholesterol, triglyceride, and fasting plasma glucose were investigated in all subjects. Blood samples were drawn with minimal trauma from an antecubital vein in the morning after an overnight fast. Blood pressure was measured to the nearest $2 \mathrm{mmHg}$ using an appropriately sized cuff and a standard mercury sphygmomanometer in a sitting position by trained nurses. Subjects took at least a 10-min rest before the measurement was taken. Biochemical markers such as total cholesterol, triglyceride, and fasting glucose were analyzed by a biochemical autoanalyzer (Beckman Coulter, CA, USA).

\section{Genotyping}

DNA was isolated from blood samples using QIAamp DNA blood kit following the manufacturer's instructions (Qiagen, Valencia, CA, USA). To extract DNA, we used $200 \mu \mathrm{l}$ of blood which was further solved in $200 \mu \mathrm{l}$ of distilled water (Wu et al. 2009). Before PCR reaction, part of the extracted DNA was diluted into a concentration of $10 \mu \mathrm{g} / \mu \mathrm{l}$. The qualities of isolated genomic DNAs were checked using the agarose gel electrophoresis and the quantities determined using spectrophotometry.

All SNP genotypings were performed using the Taqman SNP genotyping assay (ABI: Applied Biosystems Inc., Foster City, CA, USA). The primers and probes of SNPs were from $\mathrm{ABI}$ assay on demand kit. Reactions were carried out according to the manufacturer's protocol. The probe fluorescence signal detection was performed using the ABI Prism 7900 Real-Time PCR System. 
Statistical analysis

We analyzed the categorical data using the chi-square test. Differences for continuous variables were compared using the Student's $t$ test. Genotype frequencies were evaluated for Hardy-Weinberg equilibrium using a $\chi^{2}$ goodness-of-fit test. Logistic regression was conducted to adjust for covariates. Odds ratios (ORs) and their $95 \%$ confidence intervals (CIs) were evaluated. As the method adopted in this study was similar to the previous studies (Grudell et al. 2008; Hauner et al. 2003; Hsiao et al. 2009) of investigating the GNB3 rs5443 polymorphism, we performed odds ratio analysis by comparing CC genotypes with the combined CT and TT genotypes. The criterion for significance was set at $P<0.05$ for all tests. Data are presented as mean \pm standard deviation.

\section{Results}

Table 1 describes the demographic and clinical characteristics of the study population. The GNB3 rs5443 SNP was evaluated for its contribution to obesity in the complete sample population, including 505 normal subjects (BMI < 24), 291 overweight subjects $(24 \leqq$ BMI < 27), and 176 obese subjects (BMI $\geqq 27$ ). As shown in Table 1 , unrelated obese and normal subjects did not have similar distribution of $\operatorname{sex}(P<0.001)$. In addition, the distribution of age in these two groups were well matched $(P=0.96)$. The values of systolic and diastolic blood pressures were significantly different between obese and normal subjects $(P<0.001$ and $P<0.001$, respectively). BMI $(P<0.001)$, triglyceride $(P<0.001)$, waist $(P<0.001)$, and fasting glucose $(P=0.009)$ were also not similar between obese and normal subjects. However, there was no significant difference in total cholesterol in these two groups $(P=0.264)$.

Further, there were significant differences in sex, BMI, triglyceride, waist, systolic and diastolic blood pressures between overweight and normal subjects (Table 1, all $P<0.001$, respectively). The distribution of age in these two groups were well matched $(P=0.96)$. The values of total cholesterol were also significantly different between these two groups $(P=0.017)$. However, fasting glucose was similar between overweight and normal subjects $(P=0.081)$.

In addition, we assessed whether the GNB3 rs5443 SNP could influence obesity-related metabolic traits in the study population. Table 2 describes the demographic and clinical characteristics of the study population separated by genotypes. In the complete sample population, triglyceride was significantly higher in the $\mathrm{CC}$ homozygotes than in the combined CT + TT genotypes $\quad(128.2 \pm 93.2$ vs.
$114.3 \pm 79.1 \mathrm{mg} / \mathrm{dl} ; \quad P=0.041)$ as shown in Table 2 . Moreover, total cholesterol was significantly higher in the $\mathrm{CC}$ homozygotes than in the combined CT $+\mathrm{TT}$ genotypes $(194.5 \pm 36.8$ vs. $187.9 \pm 33.0 \mathrm{mg} / \mathrm{dl} ; P=0.019)$. There was no evidence of association between GNB3 rs5443 and other obesity-related measures and metabolic traits in the complete sample population.

Table 3 shows the genotype and allele distributions of the GNB3 rs5443 SNP in the case and control groups for the complete sample population with (a) obese versus normal subjects and (b) overweight versus normal subjects. Among the obese and normal subjects, no association with obesity was detected in the GNB3 rs5443 polymorphism. Further, the GNB3 rs5443 SNP did not exhibit any significant association with overweight among the subjects.

For the complete sample population, the genotype frequency distribution for the GNB3 rs5443 SNP was in Hardy-Weinberg equilibrium $(P=0.376)$. In addition, the genotype frequency distribution for the GNB3 rs5443 SNP was in Hardy-Weinberg equilibrium among the normal subjects $(P=0.188)$ as well as among the overweight subjects $(P=0.134)$. However, the obese subjects were not in accordance with the Hardy-Weinberg equilibrium $(P=0.038)$. We also found that the genotype frequencies of the GNB3 rs5443 SNP (that is, CC $=18.1 \%$, $\mathrm{CT}=50.5 \%$, TT $=31.4 \%$ ) shown in this study did not deviate from the reported genotype frequencies in Taiwanese in the literature by comparing with Tsai et al.'s study (2004) (that is, $\mathrm{CC}=20.7 \%, \mathrm{CT}=50.6 \%$, $\mathrm{TT}=28.7 \% ; P=0.791)$.

Moreover, the odd ratio analysis did not show the risk genotypes of variants in GNB3 rs5443 among the obese and normal subjects, after adjustment for covariates including gender, BMI, triglyceride, waist, systolic and diastolic blood pressures, and fasting glucose (Table 4). The odd ratio analysis either did not show the risk genotypes of variants in GNB3 rs5443 among the overweight and normal subjects, after adjustment for covariates including gender, BMI, triglyceride, waist, systolic and diastolic blood pressures, and total cholesterol (Table 4). As shown in Table 4 the effects of the risk genotypes on obesity were not influenced by covariates.

Finally, we assessed whether the GNB3 rs5443 SNP could influence obesity-related metabolic traits among three sample populations, including normal, obese, and overweight subjects as shown in Tables 5,6 , and 7 . In the normal subjects, triglyceride was significantly higher in the CC homozygotes than in the combined CT + TT genotypes $(109.6 \pm 76.9$ vs. $92.7 \pm 57.0 \mathrm{mg} / \mathrm{dl} ; P=0.018)$ as shown in Table 5. Moreover, total cholesterol was significantly higher in the $\mathrm{CC}$ homozygotes than in the combined CT + TT genotypes $(195.1 \pm 39.6$ vs. $184.8 \pm 33.5 \mathrm{mg} /$ $\mathrm{dl} ; P=0.011)$. There was no evidence of association 
Table 1 Demographic and clinical characteristics of study subjects

Data are presented as mean \pm standard deviation $B M I$ body mass index

${ }^{a} P$ values are obtained by comparing the normal subjects with overweight subjects

${ }^{b} P$ values are obtained by comparing the normal subjects with obesity subjects

Table 2 Demographic and clinical characteristics of study subjects by genotypes

Data are presented as mean \pm standard deviation $B M I$ body mass index

$P$ values are obtained by comparing the subjects of the combined CT + TT genotypes with those of the $\mathrm{CC}$ genotype

\begin{tabular}{llllrl}
\hline Characteristic & $\begin{array}{l}\text { Normal } \\
\text { BMI }<24\end{array}$ & $\begin{array}{l}\text { Overweight } \\
24 \leqq \text { BMI }<27\end{array}$ & $\begin{array}{l}\text { Obesity BMI } \\
\text { No27 }\end{array}$ & $P$ value $^{\mathrm{a}}$ & $P$ value $^{\mathrm{b}}$ \\
\hline No. of subjects & 505 & 291 & 176 & \\
Age (years) & $39.7 \pm 12.3$ & $40.9 \pm 10.9$ & $39.7 \pm 10.9$ & 0.126 & 0.960 \\
Gender (male \%) & $50.9 \%$ & $70.1 \%$ & $73.3 \%$ & $<0.001$ & $<0.001$ \\
BMI $\left(\mathrm{kg} / \mathrm{m}^{2}\right)$ & $21.5 \pm 1.8$ & $25.3 \pm 0.9$ & $30.1 \pm 3.2$ & $<0.001$ & $<0.001$ \\
Triglyceride (mg/dl) & $95.6 \pm 61.4$ & $131.8 \pm 86.1$ & $153.3 \pm 106.7$ & $<0.001$ & $<0.001$ \\
Waist $(\mathrm{cm})$ & $74.9 \pm 7.4$ & $84.6 \pm 5.9$ & $94.4 \pm 8.9$ & $<0.001$ & $<0.001$ \\
Systolic blood pressure (mmHg) & $122.1 \pm 14.3$ & $128.5 \pm 12.6$ & $135.2 \pm 17.6$ & $<0.001$ & $<0.001$ \\
Diastolic blood pressure (mmHg) & $78.2 \pm 9.9$ & $83.2 \pm 10.2$ & $87.4 \pm 12.5$ & $<0.001$ & $<0.001$ \\
Fasting glucose (mg/dl) & $86.6 \pm 21.3$ & $89.4 \pm 22.8$ & $91.8 \pm 25.5$ & 0.081 & 0.009 \\
Total cholesterol (mg/dl) & $186.7 \pm 34.9$ & $192.6 \pm 32.2$ & $190.1 \pm 33.1$ & 0.017 & 0.264 \\
\hline
\end{tabular}

\begin{tabular}{llllll}
\hline Characteristic & CC & CT & TT & CT + TT & $P$ value $^{\mathrm{a}}$ \\
\hline No. of subjects & 176 & 491 & 305 & 796 & \\
Age (years) & $39.7 \pm 13.0$ & $40.6 \pm 11.7$ & $39.5 \pm 10.8$ & $40.2 \pm 11.4$ & 0.650 \\
Gender (male \%) & $61.9 \%$ & $60.9 \%$ & $59.7 \%$ & $60.4 \%$ & 0.712 \\
BMI $\left(\mathrm{kg} / \mathrm{m}^{2}\right)$ & $24.5 \pm 3.9$ & $23.9 \pm 3.5$ & $24.4 \pm 3.9$ & $24.1 \pm 3.7$ & 0.266 \\
Triglyceride (mg/dl) & $128.2 \pm 93.2$ & $114.2 \pm 79.7$ & $114.3 \pm 78.2$ & $114.3 \pm 79.1$ & 0.041 \\
Waist $(\mathrm{cm})$ & $81.8 \pm 10.6$ & $81.0 \pm 9.8$ & $81.5 \pm 10.5$ & $81.2 \pm 10.1$ & 0.462 \\
$\begin{array}{l}\text { Systolic blood pressure } \\
(\mathrm{mmHg})\end{array}$ & $126.7 \pm 15.7$ & $126.4 \pm 15.8$ & $126.3 \pm 14.1$ & $126.3 \pm 15.2$ & 0.766 \\
$\begin{array}{l}\text { Diastolic blood pressure } \\
(\mathrm{mmHg})\end{array}$ & $81.9 \pm 11.2$ & $81.4 \pm 11.3$ & $81.1 \pm 10.6$ & $81.3 \pm 11.0$ & 0.482 \\
$\begin{array}{l}\text { Fasting glucose }(\mathrm{mg} / \mathrm{dl}) \\
\text { Total cholesterol }(\mathrm{mg} / \mathrm{dl})\end{array}$ & $88.6 \pm 22.5$ & $88.3 \pm 22.1$ & $88.3 \pm 23.3$ & $88.3 \pm 22.5$ & 0.875 \\
\hline
\end{tabular}

between $G N B 3$ rs5443 and other obesity-related measures and metabolic traits in the normal subjects.

Among the obese subjects, no differences in clinical or metabolic characteristics were found between the GNB3 rs5443 genotypes (Table 6). Further, there was no evidence of association between GNB3 rs5443 and obesity-related metabolic traits in the overweight subjects (Table 7).

\section{Discussion and conclusion}

Our study is the first to date that has examined whether the main effects of the GNB3 rs5443 (C825T) SNP are significantly associated with the risk of obesity and obesity-related metabolic traits among Taiwanese individuals from general health examinations. In this study, our results showed that GNB3 rs5443 was associated with obesity-related metabolic traits including both triglyceride and total cholesterol levels in the Taiwanese subjects with general health examinations. Therefore, a promising finding reported for the first time was that the GNB3 rs5443 SNP may play an important role in modulating the etiology of obesity-related metabolic traits in a Taiwanese population.

Our analyses demonstrated that the $\mathrm{CC}$ genotype of GNB3 rs5443 predicts higher obesity-related metabolic traits such as triglyceride and total cholesterol levels in the non-obese subjects, but not in the obese or overweight subjects. As shown in Tables 5, 6, and 7, both triglyceride and total cholesterol levels were significantly higher in the $\mathrm{CC}$ homozygotes than in the combined CT + TT genotypes in both the complete sample population and the normal controls, but not in the obese or overweight subjects. Consequently, the significant results in the complete sample population (Table 2) arise from the normal subjects (Table 5). In line with our results, a previous Japanese study by Ishikawa et al. (2000) showed higher cholesterol levels in carriers with the $\mathrm{T}$ allele of the GNB3 rs5443 SNP. Still, these previous findings disagreed with the notion that the $\mathrm{T}$ allele was associated with lower cholesterol levels, even though their findings were similar to the present results. We assumed that this may be partly owing to the differences in the T allele frequency of the GNB3 rs5443 SNP between the present Taiwanese population 
Table 3 Distributions of genotypes and alleles between the case and control groups in (a) the obese and normal subjects; (b) the overweight and normal subjects

\begin{tabular}{|c|c|c|c|c|c|c|}
\hline \multirow[t]{2}{*}{ Gene } & \multirow[t]{2}{*}{ SNP } & \multirow{2}{*}{$\begin{array}{l}\text { Allele }(\mathrm{C} / \mathrm{T}) \text { and Genotype } \\
(\mathrm{CC} / \mathrm{CT} / \mathrm{TT})\end{array}$} & \multirow[t]{2}{*}{ Case } & \multirow[t]{2}{*}{ Control } & \multicolumn{2}{|c|}{ Association $(P$ value $)$} \\
\hline & & & & & Allele $(\mathrm{C} / \mathrm{T})$ & Genotype $(\mathrm{CC} / \mathrm{CT}+\mathrm{TT})$ \\
\hline \multicolumn{7}{|c|}{ (a) Obese $(\mathrm{BMI} \geqq 27)$ and normal $(\mathrm{BMI}<24)$ subjects } \\
\hline \multirow[t]{2}{*}{ GNB3 } & rs5443 & $\mathrm{C} / \mathrm{T}$ & $153 / 199$ & $441 / 569$ & 0.948 & 0.136 \\
\hline & & $\mathrm{CC} / \mathrm{CT} / \mathrm{TT}$ & $40 / 73 / 63$ & $89 / 263 / 153$ & & \\
\hline \multicolumn{7}{|c|}{ (b) Overweight $(24 \leqq$ BMI $<27)$ and normal $(\mathrm{BMI}<24)$ subjects } \\
\hline \multirow[t]{2}{*}{ GNB3 } & rs5443 & $\mathrm{C} / \mathrm{T}$ & $249 / 333$ & $441 / 569$ & 0.733 & 0.595 \\
\hline & & $\mathrm{CC} / \mathrm{CT} / \mathrm{TT}$ & $47 / 155 / 89$ & $89 / 263 / 153$ & & \\
\hline
\end{tabular}

Table 4 Odds ratio analysis with odds ratios before and after adjustment for covariates in (a) the obese and normal subjects; (b) the overweight and normal subjects

\begin{tabular}{|c|c|c|c|c|c|c|}
\hline Gene & SNP & Genotypes & OR $(95 \% \mathrm{CI})$ & $P$ value & Adjusted OR (95\% CI) & $P$ value \\
\hline \multicolumn{7}{|c|}{ (a) Obese $(\mathrm{BMI} \geqq 27)$ and normal $(\mathrm{BMI}<24)$ subjects } \\
\hline GNB3 & rs5443 & $\mathrm{CC}$ versus $\mathrm{CT}+\mathrm{TT}$ & $1.37(0.90-2.09)$ & 0.137 & $1.40(0.67-2.92)$ & 0.376 \\
\hline \multicolumn{7}{|c|}{ (b) Overweight $(24 \leqq \mathrm{BMI}<27)$ and normal $(\mathrm{BMI}<24)$ subjects } \\
\hline GNB3 & rs5443 & $\mathrm{CC}$ versus $\mathrm{CT}+\mathrm{TT}$ & $0.90(0.61-1.33)$ & 0.595 & $0.85(0.53-1.37)$ & 0.502 \\
\hline
\end{tabular}

Among the obese and normal subjects, analysis is obtained after adjustment for covariates including gender, BMI, triglyceride, waist, systolic and diastolic blood pressures, and fasting glucose

Among the overweight and normal subjects, analysis is obtained after adjustment for covariates including gender, BMI, triglyceride, waist, systolic and diastolic blood pressures, and total cholesterol

$C I$ confidence interval, $O R$ odds ratio

$(56.6 \%)$ and the Japanese study sample by Ishikawa et al. (48.7\%). On the contrary, two other Japanese studies by Hayakawa et al. (2007) and Suwazono et al. (2006) reported no evidence of association between GNB3 rs5443 and total cholesterol levels in the subject with general health examinations. Hayakawa et al. (2007) also found that GNB3 rs5443 was not associated with triglyceride. Possible explanations for the discrepancies in these studies may be the use of insufficient sample sizes, varied phenotype assessment, differences in ethnicity, different study designs, and a lack of adjustment for confounding effects (Andersen et al. 2006).

The GNB3 rs5443 polymorphism has been widely implicated in affecting obesity risk, although genetic evidence of its effect on obesity has been inconsistent. In this study, single locus analyses did not show significant main effects of GNB3 rs5443 (in either genotypic test or odds ratio analysis) on the risk of obesity or overweight in the subjects. Our results were in agreement with those of several other studies (Andersen et al. 2006; Hayakawa et al. 2007; Suwazono et al. 2004). A previous study by Andersen et al. (2006) suggested that there is no major involvement of the GNB3 rs5443 polymorphism in obesity in white Danish subjects. Hayakawa et al. (2007) also demonstrated that the GNB3 rs5443 polymorphism is unlikely to influence obesity in Japanese subjects who underwent general health examinations. Furthermore, Suwazono et al. (2004) reported a lack of association between GNB3 rs5443 and overweight in Japanese workers with general health examinations. Although Brand et al. (2003) reported that in men, but not in women, the $\mathrm{T}$ allele and TT genotype in the GNB3 rs5443 SNP were more prevalent in obese subjects than in normal subjects in a German population, they showed that the genotypic and allelic frequencies in GNB3 rs5443 were not significantly different between normal and overweight subjects.

In contrast to our reports in this study and the abovementioned (Andersen et al. 2006; Hayakawa et al. 2007; Suwazono et al. 2004) studies, the observation of Siffert et al. (1999) in their studies suggested that there was a potential association between the T allele of GNB3 rs5443 and obesity in individuals of different ethnicity, including Germans, Chinese, and black South Africans. The potential reasons for the discrepancies between Siffert et al. (1999) and our results may be the sample sizes, different ethnicities, and different study designs. Further, we speculated that this may, in part, be due to the differences across ethnic groups in the haplotypes of GNB3 rs5443 with other SNPs in the GNB3 gene so that other variants around GNB3 rs5443 may influence the prevalence of overweight or obesity (Suwazono et al. 2004). Another potential reason for the discrepancies is that there are large disparities in the 
Table 5 Metabolic and clinical characteristics in the normal subjects according to GNB3 genotypes

\begin{tabular}{llll}
\hline Characteristic & $\mathrm{CT}+\mathrm{TT}$ & $\mathrm{CC}$ & $P$ value \\
\hline No. of subjects & 416 & 89 & \\
Age (years) & $39.5 \pm 11.9$ & $40.3 \pm 14.3$ & 0.610 \\
Gender (male \%) & $51.2 \%$ & $49.4 \%$ & 0.763 \\
BMI $\left(\mathrm{kg} / \mathrm{m}^{2}\right)$ & $21.5 \pm 1.8$ & $21.5 \pm 1.7$ & 0.887 \\
Triglyceride $(\mathrm{mg} / \mathrm{dl})$ & $92.7 \pm 57.0$ & $109.6 \pm 76.9$ & 0.018 \\
Waist $(\mathrm{cm})$ & $75.3 \pm 7.3$ & $74.8 \pm 7.3$ & 0.607 \\
Systolic blood pressure & $122.2 \pm 14.3$ & $121.6 \pm 14.8$ & 0.714 \\
$\quad(\mathrm{mmHg})$ & & & \\
$\begin{array}{l}\text { Diastolic blood pressure } \\
\quad(\mathrm{mmHg})\end{array}$ & $78.4 \pm 9.9$ & $77.5 \pm 9.9$ & 0.453 \\
$\begin{array}{l}\text { Fasting glucose }(\mathrm{mg} / \mathrm{dl}) \\
\text { Total cholesterol }(\mathrm{mg} / \mathrm{dl})\end{array}$ & $86.6 \pm 21.1$ & $86.7 \pm 21.7$ & 0.963 \\
\hline
\end{tabular}

Data are presented as mean \pm standard deviation

$B M I$ body mass index

$P$ values are obtained by comparing the subjects of the combined $\mathrm{CT}+\mathrm{TT}$ genotypes with those of the CC genotype

T allele frequency of GNB3 rs5443 between populations of different ethnicities, ranging from 65 to $91 \%$ among Africans, 21-35\% in Europeans, 42-52\% among Asians, and $56.6 \%$ in the present Taiwanese population in our study (Andersen et al. 2006; Siffert et al. 1999).

In addition, previous studies (Grudell et al. 2008; Hauner et al. 2003; Hsiao et al. 2009) in pharmacogenetics suggested that the GNB3 rs5443 SNP could influence weight reduction and body composition change under sibutramine therapy. The observation of Grudell et al. (2008) and Hsiao et al. (2009) in their studies showed that

Table 6 Metabolic and clinical characteristics in the obese subjects according to GNB3 genotypes

\begin{tabular}{llll}
\hline Characteristic & CT + TT & CC & $P$ value \\
\hline No. of subjects & 136 & 40 & \\
Age (years) & $40.2 \pm 11.1$ & $38.0 \pm 10.4$ & 0.267 \\
Gender (male \%) & $72.8 \%$ & $75.0 \%$ & 0.782 \\
BMI $\left(\mathrm{kg} / \mathrm{m}^{2}\right)$ & $30.1 \pm 3.2$ & $30.1 \pm 3.1$ & 0.974 \\
Triglyceride $(\mathrm{mg} / \mathrm{dl})$ & $151.7 \pm 102.5$ & $155.3 \pm 120.0$ & 0.853 \\
Waist $(\mathrm{cm})$ & $93.7 \pm 9.2$ & $93.7 \pm 9.4$ & 0.975 \\
$\begin{array}{l}\text { Systolic blood pressure } \\
\quad(\mathrm{mmHg})\end{array}$ & $135.3 \pm 17.9$ & $134.8 \pm 16.7$ & 0.866 \\
$\begin{array}{l}\text { Diastolic blood pressure } \\
\quad(\mathrm{mmHg})\end{array}$ & $86.9 \pm 12.7$ & $89.2 \pm 11.9$ & 0.322 \\
$\begin{array}{l}\text { Fasting glucose }(\mathrm{mg} / \mathrm{dl}) \\
\text { Total cholesterol }(\mathrm{mg} / \mathrm{dl})\end{array}$ & $91.1 \pm 23.6$ & $93.8 \pm 30.6$ & 0.557 \\
\end{tabular}

Data are presented as mean \pm standard deviation

$B M I$ body mass index

$P$ values are obtained by comparing the subjects of the combined $\mathrm{CT}+\mathrm{TT}$ genotypes with those of the CC genotype
Table 7 Metabolic and clinical characteristics in the overweight subjects according to GNB3 genotypes

\begin{tabular}{llll}
\hline Characteristic & CT + TT & CC & $P$ value \\
\hline No. of subjects & 244 & 47 & \\
Age (years) & $41.2 \pm 10.5$ & $40.1 \pm 12.7$ & 0.532 \\
Gender (male \%) & $69.3 \%$ & $74.5 \%$ & 0.475 \\
BMI $\left(\mathrm{kg} / \mathrm{m}^{2}\right)$ & $25.3 \pm 0.9$ & $25.3 \pm 0.8$ & 0.980 \\
Triglyceride $(\mathrm{mg} / \mathrm{dl})$ & $130.4 \pm 85.3$ & $139.0 \pm 90.9$ & 0.532 \\
Waist $(\mathrm{cm})$ & $84.3 \pm 6.0$ & $85.0 \pm 4.7$ & 0.488 \\
Systolic blood pressure & $128.4 \pm 12.4$ & $129.5 \pm 13.5$ & 0.573 \\
$\quad(\mathrm{mmHg})$ & & & \\
Diastolic blood pressure & $83.1 \pm 10.4$ & $84.0 \pm 9.2$ & 0.554 \\
$\quad(\mathrm{mmHg})$ & & & \\
Fasting glucose $(\mathrm{mg} / \mathrm{dl})$ & $89.7 \pm 24.1$ & $87.8 \pm 14.2$ & 0.604 \\
Total cholesterol $(\mathrm{mg} / \mathrm{dl})$ & $193.1 \pm 32.6$ & $190.1 \pm 29.7$ & 0.562 \\
\hline
\end{tabular}

Data are presented as mean \pm standard deviation

$B M I$ body mass index

$P$ values are obtained by comparing the subjects of the combined $\mathrm{CT}+\mathrm{TT}$ genotypes with those of the CC genotype

the GNB3 TT/TC genotypes were associated with greater weight loss with the sibutramine group than with the placebo group. In contrast to Grudell et al. (2008) and Hsiao et al.'s (2009) studies, a report by Hauner et al. (2003) indicated that individuals with the GNB3 CC genotype were associated with more weight loss from sibutramine administration. In addition, Grudell et al.'s (2008) analyses were consistent with Hsiao et al.'s (2009) results that treatment with sibutramine resulted in significantly greater reduction in body fat for specific GNB3 TC/TT genotypes.

Besides the statistical significance, we were concerned with the potential biological mechanism between GNB3 rs5443 and obesity. Heterotrimeric G-proteins play a key role in transmembrane signaling systems that allow cells to receive information from extracellular stimuli such as hormones or neurotransmitters (Preininger and Hamm 2004; Wettschureck and Offermanns 2005). The heterotrimeric G-protein consists of an alpha-subunit as well as of a beta- and a gamma-subunit, and it involves metabolic processes such as adipocyte lipolysis and lipogenesis (Preininger and Hamm 2004; Wettschureck and Offermanns 2005). Su et al. (1993) also suggested that increased signaling by G-proteins stimulates adipogenesis, which is the development of fat cells from preadipocytes, and thus may lead to obesity (Siffert et al. 1999). In addition, the T allele of the rs5443 SNP results in an in-frame deletion of 41 amino acids and enhances intracellular signal transduction via various G-protein-coupled receptors (Siffert et al. 1998).

One limitation of this study is that these findings may not be generalizable to other populations, and ethnically matched studies would be necessary to know whether such 
association is found in non-Taiwanese subjects (Lin et al. 2009a, b). Second, the small size of the sample does not allow drawing definite conclusions (Huang et al. 2009). In the future work, large prospective clinical trials are necessary in order to answer whether this SNP is reproducibly associated with obesity and obesity-related metabolic traits.

In conclusion, our study has tested the association of GNB3 rs5443 SNP with obesity and obesity-related metabolic traits in Taiwanese subjects with general health examinations. Our findings support the possibilities that the GNB3 rs5443 SNP may be a determinant of obesity-related metabolic traits. Independent replications in large sample sizes are needed to confirm the role of the GNB3 rs5443 polymorphism found in this study.

Acknowledgments The authors extend their sincere thanks to Vita Genomics, Inc., and SBIR grants from the Department of Economic Affairs in Taiwan for funding this research.

Conflict of interest The authors have no conflicts of interest that are directly relevant to the content of this study.

\section{References}

Andersen G, Overgaard J, Albrechtsen A, Glümer C, Borch-Johnsen K, Jørgensen T, Hansen T, Pedersen O (2006) Studies of the association of the GNB3 $825 \mathrm{C}>\mathrm{T}$ polymorphism with components of the metabolic syndrome in white Danes. Diabetologia 49:75-82

Benjafield AV, Lin RC, Dalziel B, Gosby AK, Caterson ID, Morris BJ (2001) G-protein beta3 subunit gene splice variant in obesity and overweight. Int J Obes Relat Metab Disord 25:777-780

Brand E, Wang JG, Herrmann SM, Staessen JA (2003) An epidemiological study of blood pressure and metabolic phenotypes in relation to the Gbeta3 C825T polymorphism. J Hypertens 21:729-737

Cabrera-Vera TM, Vanhauwe J, Thomas TO, Medkova M, Preininger A, Mazzoni MR, Hamm HE (2003) Insights into G protein structure, function, and regulation. Endocr Rev 24:765-781

Chu NF (2005) Prevalence of obesity in Taiwan. Obes Rev 6:271-274

Grudell AB, Sweetser S, Camilleri M, Eckert DJ, Vazquez-Roque MI, Carlson PJ, Burton DD, Braddock AE, Clark MM, Graszer KM, Kalsy SA, Zinsmeister AR (2008) A controlled pharmacogenetic trial of sibutramine on weight loss and body composition in obese or overweight adults. Gastroenterology 135:1142-1154

Hauner H, Meier M, Jöckel KH, Frey UH, Siffert W (2003) Prediction of successful weight reduction under sibutramine therapy through genotyping of the G-protein beta3 subunit gene (GNB3) C825T polymorphism. Pharmacogenetics 13:453-459

Hayakawa T, Takamura T, Abe T, Kaneko S (2007) Association of the C825T polymorphism of the G-protein beta3 subunit gene with hypertension, obesity, hyperlipidemia, insulin resistance, diabetes, diabetic complications, and diabetic therapies among Japanese. Metabolism 56:44-48

Hebebrand J, Volckmar AL, Knoll N, Hinney A (2010) Chipping away the 'missing heritability': GIANT steps forward in the molecular elucidation of obesity-but still lots to go. Obes Facts 3:294-303

Hegele RA, Anderson C, Young TK, Connelly PW (1999) G-protein beta3 subunit gene splice variant and body fat distribution in Nunavut Inuit. Genome Res 9:972-977
Hsiao DJ, Wu LS, Huang SY, Lin E (2009) Weight loss and body fat reduction under sibutramine therapy in obesity with the C825T polymorphism in the GNB3 gene. Pharmacogenet Genomics 19:730-733

Huang LC, Hsu SY, Lin E (2009) A comparison of classification methods for predicting chronic fatigue syndrome based on genetic data. J Transl Med 7:81

Ishikawa K, Imai Y, Katsuya T, Ohkubo T, Tsuji I, Nagai K, Takami S, Nakata Y, Satoh H, Hisamichi S, Higaki J, Ogihara T (2000) Human G-protein beta3 subunit variant is associated with serum potassium and total cholesterol levels but not with blood pressure. Am J Hypertens 13:140-145

Kelly T, Yang W, Chen CS, Reynolds K, He J (2008) Global burden of obesity in 2005 and projections to 2030. Int J Obes (Lond) 32:1431-1437

Klenke S, Kussmann M, Siffert W (2011) The GNB3 C825T polymorphism as a pharmacogenetic marker in the treatment of hypertension, obesity, and depression. Pharmacogenet Genomics 21:594-606

Lin E, Chen PS, Chang HH, Gean PW, Tsai HC, Yang YK, Lu RB (2009a) Interaction of serotonin-related genes affects short-term antidepressant response in major depressive disorder. Prog Neuropsychopharmacol Biol Psychiatry 33:1167-1172

Lin E, Pei D, Huang YJ, Hsieh CH, Wu LS (2009b) Gene-gene interactions among genetic variants from obesity candidate genes for nonobese and obese populations in type 2 diabetes. Genet Test Mol Biomarkers 13:485-493

Loos RJ (2009) Recent progress in the genetics of common obesity. Br J Clin Pharmacol 68:811-829

Ogden CL, Yanovski SZ, Carroll MD, Flegal KM (2007) The epidemiology of obesity. Gastroenterology 132:2087-2102

Poch E, Giner V, Gonzalez-Nunez D, Coll E, Oriola J, De la SA (2002) Association of the $G$ protein beta3 subunit $T$ allele with insulin resistance in essential hypertension. Clin Exp Hypertens 24:345-353

Preininger AM, Hamm HE (2004) G protein signaling: insights from new structures. Sci STKE 2004:re3

Siffert W (2005) G protein polymorphisms in hypertension, atherosclerosis, and diabetes. Annu Rev Med 56:17-28

Siffert W, Rosskopf D, Moritz A, Wieland T, Kaldenberg-Stasch S, Kettler N, Hartung K, Beckmann S, Jakobs KH (1995) Enhanced $\mathrm{G}$ protein activation in immortalized lymphoblasts from patients with essential hypertension. J Clin Invest 96:759-766

Siffert W, Rosskopf D, Siffert G, Busch S, Moritz A, Erbel R, Sharma AM, Ritz E, Wichmann HE, Jakobs KH, Horsthemke B (1998) Association of a human G-protein beta3 subunit variant with hypertension. Nat Genet 18:45-48

Siffert W, Forster P, Jöckel KH, Mvere DA, Brinkmann B, Naber C, Crookes R, Du P, Heyns A, Epplen JT, Fridey J, Freedman BI, Müller N, Stolke D, Sharma AM, Al Moutaery K, Grosse-Wilde H, Buerbaum B, Ehrlich T, Ahmad HR, Horsthemke B, Du Toit ED, Tiilikainen A, Ge J, Wang Y, Rosskopf D et al (1999a) Worldwide ethnic distribution of the $G$ protein beta3 subunit $825 \mathrm{~T}$ allele and its association with obesity in Caucasian, Chinese, and Black African individuals. J Am Soc Nephrol 10:1921-1930

Siffert W, Naber C, Walla M, Ritz E (1999b) G protein beta3 subunit $825 \mathrm{~T}$ allele and its potential association with obesity in hypertensive individuals. J Hypertens 17:1095-1098

Stefan N, Stumvoll M, Machicao F, Koch M, Häring HU, Fritsche A (2004) C825T polymorphism of the G protein beta3 subunit is associated with obesity but not with insulin sensitivity. Obes Res 12:679-683

Su HL, Malbon CC, Wang HY (1993) Increased expression of Gi a2 in mouse embryo stem cells promotes terminal differentiation to adipocytes. Am J Physiol 265:C1729-C1735 
Suwazono Y, Okubo Y, Kobayashi E, Miura K, Morikawa Y, Ishizaki M, Kido T, Nakagawa H, Nogawa K (2004) Lack of association between human G-protein beta3 subunit variant and overweight in Japanese workers. Obes Res 12:4-8

Suwazono Y, Kobayashi E, Uetani M, Miura K, Morikawa Y, Ishizaki M, Kido T, Nakagawa H, Nogawa K (2006) G-protein beta3 subunit gene variant (C825T) is unlikely to have a significant influence on serum total cholesterol level in Japanese workers. Clin Exp Hypertens 28:47-56

Tsai SJ, Yu YW, Lin CH, Wang YC, Chen JY, Hong CJ (2004) Association study of adrenergic beta3 receptor (Trp64Arg) and
G-protein beta3 subunit gene (C825T) polymorphisms and weight change during clozapine treatment. Neuropsychobiology 50:37-40

Wettschureck N, Offermanns S (2005) Mammalian G proteins and their cell type specific functions. Physiol Rev 85:1159-1204

Wu LS, Hsieh CH, Pei D, Hung YJ, Kuo SW, Lin E (2009) Association and interaction analyses of genetic variants in ADIPOQ, ENPP1, GHSR, PPAR \{gamma $\}$ and TCF7L2 genes for diabetic nephropathy in a Taiwanese population with type 2 diabetes. Nephrol Dial Transpl 24:3360-3366 